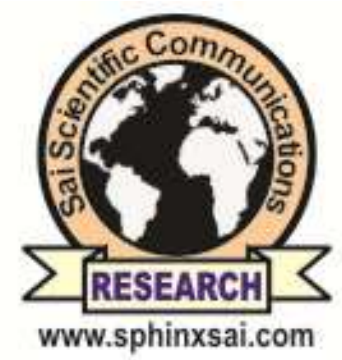

\title{
Formulation and Evaluation of Mupirocin Nimosomal Gel for Topical Drug Delivery System
}

\author{
Rajesh Akki ${ }^{1 *}$, Munagala Gayatri Ramya ${ }^{2}$, \\ K Navyasri ${ }^{1}$, Singaram Kathirvel ${ }^{3}$ \\ 1.Department of Pharmaceutics, Hindu College of Pharmacy, Guntur, India \\ 2.University College of Pharmaceutical Sciences, Acharya Nahajuna University, \\ Nagarjuna Nagar, Guntur 522 510, India \\ ${ }^{3}$ National College of Pharmacy, Manassery P.O, Mukkam, Kozhikode-673602, \\ Kerala, India
}

\begin{abstract}
The present study was to formulate and evaluate the mupirocin niosomal gel using surfactants span 80 \& tween 80 for the preparation of niosomes. Mupirocin entrapped niosomes were prepared by ether injection method and transmembrane $\mathrm{pH}$ gradient drug uptake process. Niosomes were prepared by altering the ratios between various non-ionic surfactants (span $80 \&$ tween 80 ) whereas the concentration of cholesterol and drug was kept constant. The prepared niosomes were characterized for size, shape, entrapment efficiency, invitro drug release studies. The highest entrapment efficiency $(99.17 \%)$ and drug release (96.14\%) was obtained for tween 80 (1:5:5) prepared by transmembrane $\mathrm{pH}$ gradient method. The best formulation among the two techniques was selected for incorporated into gel formulation. The prepared niosomal gel and plain gel were subjected to evaluation studies like drug content, invitro drug diffusion studies. The studies were demonstrated that niosomal gel was shown beter pharmacological activity than the conventional mupirocin gel. Based on the results it was concluded that niosomal preparations offers more advantageous than the conventional preparations.
\end{abstract}

Keywords : Mupirocin, Niosomes, non-ionic surfactants (span 80, tween 80), Carbopol.

\section{Introduction:}

The present work aims to deliver the drug Mupirocin to the bacterial affected cells. This targeting can be achieved by formulating drug as niosomal transdermal gel, which prolongs the circulation of drug. Niosomes are microscopic lamellar structures formed on admixture of cholesterol and single alkyl chain non-ionic surfactant with subsequent hydration in aqueous media. ${ }^{1}$

Rajesh Akki et al /International Journal of PharmTech Research, 2020,13(2): 07-17. 
Recently niosomes are gaining popularity in the field of topical and transdermal drug delivery because of its special characteristic features like increasing penetration of drugs, acting as local depot to provide sustained release and serving as a solubilizing matrix for both hydrophilic and lipophilic drugs. ${ }^{2,3}$ By delivering the drug terbinafine hydrochloride in topical gel form systemic toxicity can be reduced. Mupirocin is used to treat skin infections such as impetigo or a "staph" infection of the skin. Impetigo (im-puh-TIE-go) is a common and highly contagious skin infection that mainly affects infants and children. Impetigo usually appears as red sores on the face, especially around a child's nose and mouth, and on hands and feet. ${ }^{4}$

\section{Materials and Methods:}

Mupirocin was obtained as a gift sample by Yarrow chem. Products, Mumbai. Cholesterol, span 80 \& tween 80 were purchased from Loba chemicals Ltd. Mumbai, Carbopol 934 obtained from Merck-specialities Pvt Ltd, Mumbai. All the materials and solvents used were of analytical grade.

\subsection{Preparation of Niosomes:}

Mupirocin loaded niosomes were prepared by two methods.

a) Transmembrane $\mathrm{pH}$ gradient drug uptake process

b) Ether injection method.

a) Transmembrane $\mathrm{pH}$ gradient drug uptake process ${ }^{5,6}$

In this method, surfactant and cholesterol are dissolved in chloroform and evaporated to form a thin film on the wall of a round bottomed flask. The film is hydrated with $300 \mathrm{~mm}$ citric acid $(\mathrm{pH} 4)$ by vortex mixing and the resulting product is freeze-thawed ( 3 Times) and sonicated. To this noisome suspension $5 \mathrm{ml}$ of aqueous solution containing $1 \mathrm{mg} / \mathrm{ml}$ drug was added and vortexed. The $\mathrm{pH}$ of the sample was raised to 7-7.2 with $1 \mathrm{ml}$ disodium hydrogen phosphate. Then heated the suspension for $10 \mathrm{~min}$ at $60^{\circ} \mathrm{C}$ to give niosomes. Formulation codes and their composition prepared by transmembrane $\mathrm{pH}$ gradient method was given in the table no. 1

\section{b) Ether injection method ${ }^{7-10}$}

Drug, span 80 and Tween 80, Cholesterol were taken in Prescribed ratio (1:4:4, 1:5:4) in a $250 \mathrm{ml}$ beaker. The mixture was dissolved in diethyl ether and methanol $(8: 2)$ solution and slowly injected through 14gauge needle into a beaker containing Mupirocin in $10 \mathrm{ml}$ Phosphate buffer $\mathrm{pH}$ 7.4. The temperature maintained during the injection was $40-60^{\circ} \mathrm{C}$. The differences in temperature between phases cause rapid vaporization of ether, methanol resulting in spontaneous vesiculation. Formulation codes and their composition prepared by ether injection method was given in the table no. 2

Table 1. List of formulations prepared by transmembrane pH gradient drug uptake process

\begin{tabular}{|l|l|l|l|l|}
\hline $\begin{array}{l}\text { Formulation/ } \\
\text { Ingredients (mg) }\end{array}$ & $\begin{array}{l}\text { F5 } \\
(\mathbf{1 : 4 : 5 )}\end{array}$ & $\begin{array}{l}\text { F6 } \\
\mathbf{( 1 : 5 : 5 )}\end{array}$ & $\begin{array}{l}\text { F7 } \\
\mathbf{( 1 : 4 : 5 )}\end{array}$ & $\begin{array}{l}\text { F8 } \\
(\mathbf{1 : 5}: 5)\end{array}$ \\
\hline Drug & 20 & 20 & 20 & 20 \\
\hline Span 80 & 80 & 100 & - & - \\
\hline Tween 80 & - & - & 80 & 100 \\
\hline Cholesterol & 80 & 80 & 80 & 80 \\
\hline
\end{tabular}

Table 2. List of formulations prepared by ether injection method

\begin{tabular}{|l|l|l|l|l|}
\hline $\begin{array}{l}\text { Formulation/ } \\
\text { Ingredients (mg) }\end{array}$ & $\begin{array}{l}\text { F1 } \\
(\mathbf{1 : 4 : 5 )}\end{array}$ & $\begin{array}{l}\text { F2 } \\
(\mathbf{1 : 5 : 5 )}\end{array}$ & $\begin{array}{l}\text { F3 } \\
\mathbf{( 1 : 4 : 5 )}\end{array}$ & $\begin{array}{l}\text { F4 } \\
(\mathbf{1 : 5}: 5)\end{array}$ \\
\hline Drug & 20 & 20 & 20 & 20 \\
\hline Span 80 & 80 & 100 & - & - \\
\hline Tween 80 & - & - & 80 & 100 \\
\hline Cholesterol & 80 & 80 & 80 & 80 \\
\hline
\end{tabular}




\section{Evaluation of Niosomes}

\subsection{Physical appearance of niosomal suspension:}

The prepared niosomal suspension was viewed by naked eye to characterize colour and physical state of suspension. Niosomal suspension was also viewed by optical microscope at $40 \mathrm{X}$ magnification, to observe crystal characteristics of suspension by spreading a thin layer of niosomal suspension on a slide and placing the cover slip on it. The appearance for each formulawas checked such as colour,consistency and fluidity andcomparison of each one with theother.

\subsection{Vesicle Size Analysis:}

Size and size distribution studies were done for niosomes. The suspension of niosomes was observed under optical microscope at 40x magnification. The sizes of 100 vesicles were measured using a calibrated ocular and stage micrometre fitted in the optical microscope.

\subsection{Vesicle morphology}

Shape and surface morphology of niosomes was studied using scanning electron microscopy (SEM). The niosomes formed were mounted on an aluminium stub with double-sided adhesive carbon tape. The vesicles were then sputter-coated with gold/palladium using a vacuum evaporator and examined with the scanning electron microscope equipped with a digital camera at $25 \mathrm{kV}$ accelerating voltage.

\subsection{Drug encapsulation efficiency determination ${ }^{11}$}

Niosomal suspension $(5 \mathrm{ml})$ was placed in a glass tube. The aqueous suspension was sonicated in a sonicator bath for $15 \mathrm{~min}$. The Mupirocin containing niosomes were separated from unentrapped drug by centrifugation at $13000 \mathrm{rpm}$ at $20^{\circ} \mathrm{C}$ for $90 \mathrm{~min}$. The supernatant was taken and diluted with phosphate buffer of $\mathrm{P}^{\mathrm{H}}$ 7.4. And the free drug concentration in the resulting solution was assayed by the UV spectroscopic method at $226 \mathrm{~nm}$. The percentage of drug encapsulation was calculated by using the following equation.

\section{$\% \mathrm{EE}=$ Total amount of the drug entrapped $/$ Total amount of the Drug initially taken $\times 100$}

\subsection{In-Vitro diffusion study ${ }^{12}$}

The In-vitro release studies on niosomal suspension was performed using open ended tube which acts like donor compartment. The capacity of receptor compartment was $100 \mathrm{ml} \mathrm{pH7.4} \mathrm{phosphate} \mathrm{buffer} \mathrm{placed} \mathrm{in}$ $250 \mathrm{ml}$ beaker. The membrane was mounted between the donor and receptor compartment. A weighed amount of niosomal suspension ( $2 \mathrm{ml}$ ) was placed on one side of the membrane. The receptor medium taken was $100 \mathrm{ml}$ of phosphate buffer of $\mathrm{pH}$ 7.4. The receptor fluid was stirred by a Teflon-coated magnetic bead fitted to a magnetic stirrer. The receiver fluid was stirred with a magnetic stirrer at a speed of $600 \mathrm{rpm}$. At each sampling interval, $(1 \mathrm{ml})$ were withdrawn and were replaced by equal volumes of fresh receptor fluid on each occasion. The Sink condition was maintained throughout the experiment. Samples withdrawn were suitably diluted and analyzed spectrophotometrically at $226 \mathrm{~nm}$. The percentage drug release was calculated using calibration curve of the drug in phosphate buffer of $\mathrm{pH}$ 7.4.

\subsection{Preparation of mupirocin standard and mupirocin entrapped niosomal gels ${ }^{13}$}

$\% \mathrm{w} / \mathrm{w}$ mupirocin niosomal gel and $1 \% \mathrm{w} / \mathrm{w}$ mupirocin standard gel were prepared, by uniformly mixing the niosomal suspension containing mupirocin and mupirocin equivalent to $1 \% \mathrm{w} / \mathrm{w}$ of mupirocin in to a gel base composed of glycerin $(1 \% \mathrm{w} / \mathrm{w})$, glycerine $(5 \% \mathrm{w} / \mathrm{w})$, triethanolamine $(0.25 \% \mathrm{w} / \mathrm{w})$, Methyl paraben $(0.1 \%$ w/w), Propyl paraben $(0.05 \%$ w/w) and Water up to Quantity sufficient. Formulation ingredients were given in the table 3 . 
Table 3. Formulation ingredients of gel

\begin{tabular}{|l|l|l|}
\hline S.No & Ingredients (mg) & For 25 gm \\
\hline 1 & $\begin{array}{l}\text { Mupirocin niosomal suspension and } \\
\text { Standard mupirocin }\end{array}$ & $1 \mathrm{gm}$ \\
\hline 2 & Carbopol 934 & $1 \mathrm{gm}$ \\
\hline 3 & Triethanolamine & $0.25 \mathrm{ml}$ \\
\hline 4 & Glycerin & $5 \mathrm{ml}$ \\
\hline 5 & Methyl paraben & $0.1 \mathrm{gm}$ \\
\hline 6 & Propyl Paraben & 0.05 gm \\
\hline 7 & Water & Upto Quantity sufficient \\
\hline
\end{tabular}

\section{Evaluation Studies of $\mathrm{Gel}^{14}$}

\section{Physical Appearance}

Clarity, colour, homogeneity and the presence of foreign particles in the niosomal gel was determined.

\section{Determination of $\mathrm{pH}$ :}

Weighed $1 \mathrm{gm}$ of gel formulation were transferred in $100 \mathrm{ml}$ of beaker and measured it by using the digital $\mathrm{pH}$ meter. $\mathrm{pH}$ of the topical gel formulation should be between $3-9$ to treat the skin infections.

\section{Spreadability: ${ }^{15}$}

The spreadability of the gel formulation was determined, by measuring diameter of $1 \mathrm{gm}$ gel between horizontal plates $(20 \times 20 \mathrm{~cm} 2)$ after 1 minute. The standardized weight tied on the upper plate was $125 \mathrm{gm}$.

\section{Viscosity}

Brookfield viscometer was used to determine the viscosity of the niosomal gel.

\section{Drug content: ${ }^{16}$}

Weighed $10 \mathrm{gm}$ of each gel formulation were transferred in $250 \mathrm{ml}$ of volumetric flask containing 20 $\mathrm{ml}$ of alcohol and stirred for $30 \mathrm{~min}$. The volume was made up to $100 \mathrm{ml}$ and filtered. $1 \mathrm{ml}$ of above solution was further diluted to $10 \mathrm{ml}$ with alcohol and again $1 \mathrm{ml}$ of the above solution was further diluted to $10 \mathrm{ml}$ with alcohol. The absorbance of the solution was measured spectrophotometrically at $226 \mathrm{~nm}$. Drug content was calculated by the following formula.

\section{Drug content $=$ Dilution factor $\times$ Absorbance/slope $* 1 / 1000$}

\section{Anti-Microbial activity: ${ }^{17}$}

\section{Agar well diffusion assay:}

The antibacterial activity of the gel was determined by agar well diffusion method. Briefly overnight bacterial culture was diluted in the Mueller-Hinton broth to obtain a bacterial suspension of $108 \mathrm{CFU} / \mathrm{ml}$. Petri plates containing $20 \mathrm{ml}$ of broth agar media were inoculated with $100 \mu \mathrm{l}$ of diluted cultures by speed plate technique and were allowed to dry in a suitable chamber. $5 \mathrm{~mm}$ well was cut using a cork borer on the surface of the inoculated agar. The gel was loaded into wells and was allowed to dry completely. The antibacterial activity was assessed by measuring the inhibition zone. 


\section{Determination of MIC \& zone of inhibition}

A minimum inhibitory zone is the lowest concentration of an antimicrobial that inhibit the growth of microorganisms after 18-24 hrs. The samples were tested at different concentrations. Sterile NA plates were prepared and $0.1 \mathrm{ml}$ of the inoculums of test organism was spread uniformly. Wells were prepared by using a sterile borer of diameter $5 \mathrm{~mm}$ and niosomal gel of different formulations is added to the well in separate petri plate aseptically. A same concentration of plain gel is also added to a separate well. A blank is prepared without adding any drug to one of the inoculated petri plates. The plates were inoculated at $35-37^{\circ} \mathrm{C}$ for $18-48$ hours, a period of time sufficient for the growth. The zone of inhibition of microbial growth around the well was measured in $\mathrm{cm}$. MIC was calculated from the fully-grown plates.

\section{In Vitro Diffusion Studies of the Gels: ${ }^{18}$}

The receptor compartment of the Franz diffusion cell was filled with $15 \mathrm{ml}$ of phosphate buffer $\mathrm{pH} 7.4$ with a magnetic bead and was stirred continuously at $100 \mathrm{rpm}$ using a magnetic stirrer Diffusion studies were carried out by placing $1 \mathrm{~g}$ of gel in the donor compartment at $37 \pm 10 \mathrm{C} .1 \mathrm{ml}$ of samples are withdrawn through the sampling port and replaced with fresh buffer at 1, 2, 3, 4, 5, 6, 8, 10, and $12 \mathrm{hrs}$. After suitable dilutions, the absorbance was measured spectrophotometrically at $226 \mathrm{~nm}$. The procedure was performed in triplicate and the average percentage of the drug released was calculated.

\section{Stability Studies of Gels:}

The prepared niosomal gel formulations were tested for stability on storing them in glass vials at $4-8^{\circ} \mathrm{C}$, $25^{\circ} \mathrm{C}$ and 40 for $45^{\circ} \mathrm{C}$ days. On 7th, 14 th and 30 days, they were evaluated for drug content and entrapment (\%). Formulations were stored at $4-8^{\circ} \mathrm{C}, 25^{\circ} \mathrm{C}$ and $40^{\circ} \mathrm{C}$ for 45 days. After 1 month of storage, the stability testing data indicated that formulations stored at $4-8^{\circ} \mathrm{C}, 250 \mathrm{C}$ and $40^{\circ} \mathrm{C}$ showed little difference in size so we can say that our formulation is stable on all temperatures.

\section{Results and Discussions}

\subsection{Optical Microscopy and vesicular determination}

The niosomal vesicles were found to be uniform in size and shape. The sizes of particles were determined by optical microscopy and the particles revealed Multilamellar, unilamellar vesicles with no agglomeration. The range of particle size found to be 2.21 to $6.83 \mu \mathrm{m}$ for all formulations. Microscopic images were shown in fig 1.

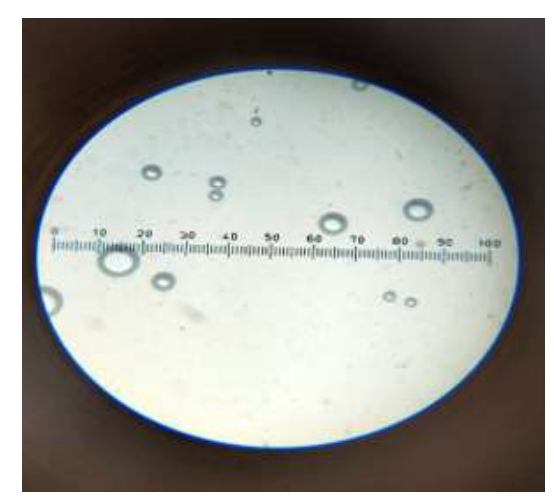

Fig.1 Microscopic image of optimised formulation

\subsection{Determination of surface morphology by SEM}

The morphology of niosomes was studied using Scanning Electron Microscopy. SEM images of Mupirocin revealed that the niosomes were spherical in shape and discrete with sharp boundaries having large internal aqueous space. SEM images of niosomes and niosomal gel were shown fig 2. From the SEM images it was found the images showed spherical vesicles and were in nano range. 

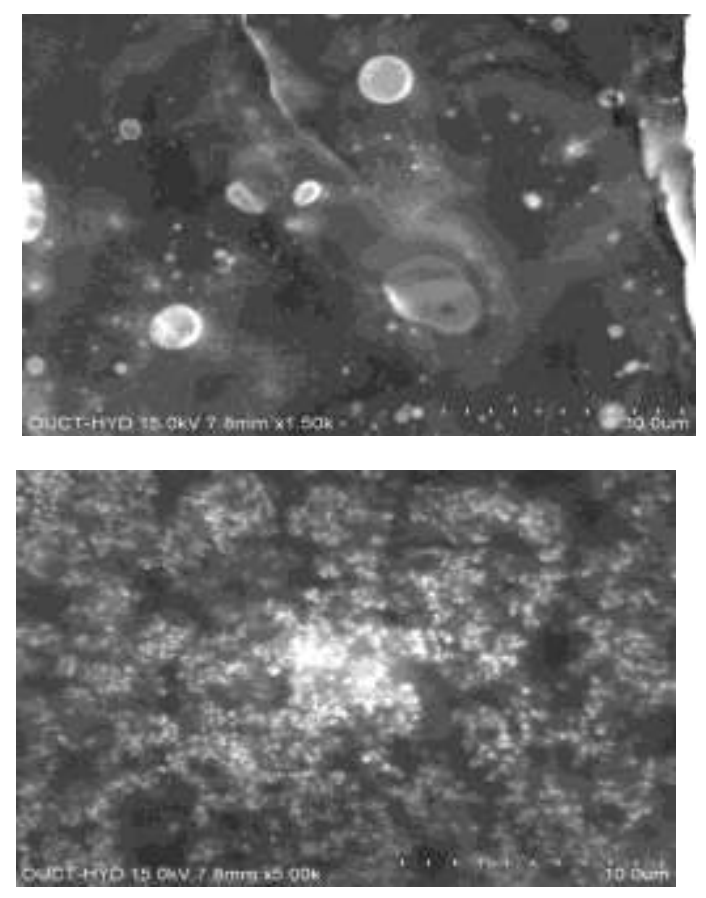

Fig 2. SEM images of niosomal formulation and gel formulation

\subsection{Entrapment Efficiency}

Encapsulation efficiency of niosomes formulations ranged from 59.28\% to $99.97 \%$. the drug encapsulation efficiency of all eight formulations are shown in fig 3 . The entrapment efficiency was found to be higher in the F8 formulation of tween 80:cholesterol (5:5) prepared by transmembrane $\mathrm{pH}$ gradient method (99.97\%), which might have optimum surfactant cholesterol ratio to provide higher entrapment of mupirocin in niosomal vesicles.

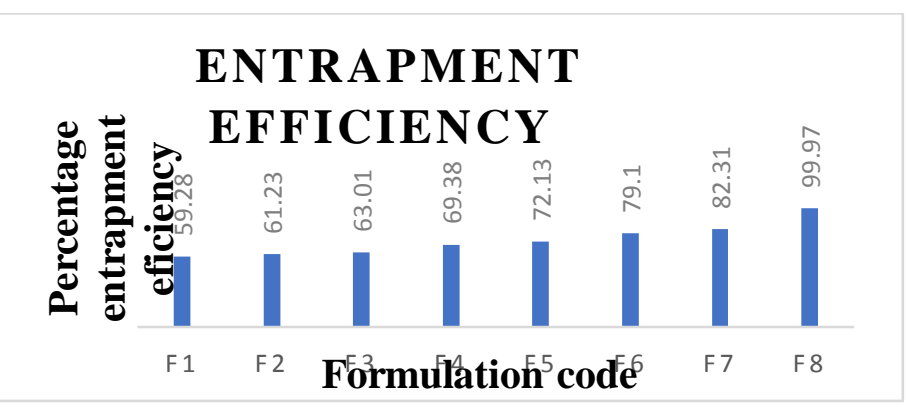

Fig 3. Comparison of entrapment efficiency of formulations

\subsection{Invitro drug diffusion studies}

The niosomal formulations of Mupirocin (F1-F8) were characterized for their drug permeation study using open ended tube through an artificial membrane. Drug diffusion study of all the formulations was carried out using Phosphate buffer of $\mathrm{pH} 7.4$ for $12 \mathrm{hrs}$ at $37 \pm 0.5^{\circ} \mathrm{C}$ with $600 \mathrm{rpm}$ speed. Samples were withdrawn at regular intervals $(01,2,3,4,5,6,8,10,12 \mathrm{~h})$. At every interval, $5 \mathrm{ml}$ of sample was withdrawn, after appropriate dilution the sample solutions were analysed at $226 \mathrm{~nm}$ for Mupirocin by using UV-Visible spectrophotometer. The result indicates that the niosomes with increased ratio of surfactant have high release rate. The percent cumulative release in $12 \mathrm{hrs}$ was found to be in the range of $52.56 \%-96.14 \%$. Comparative dissolution profiles were shown in fig 4. 


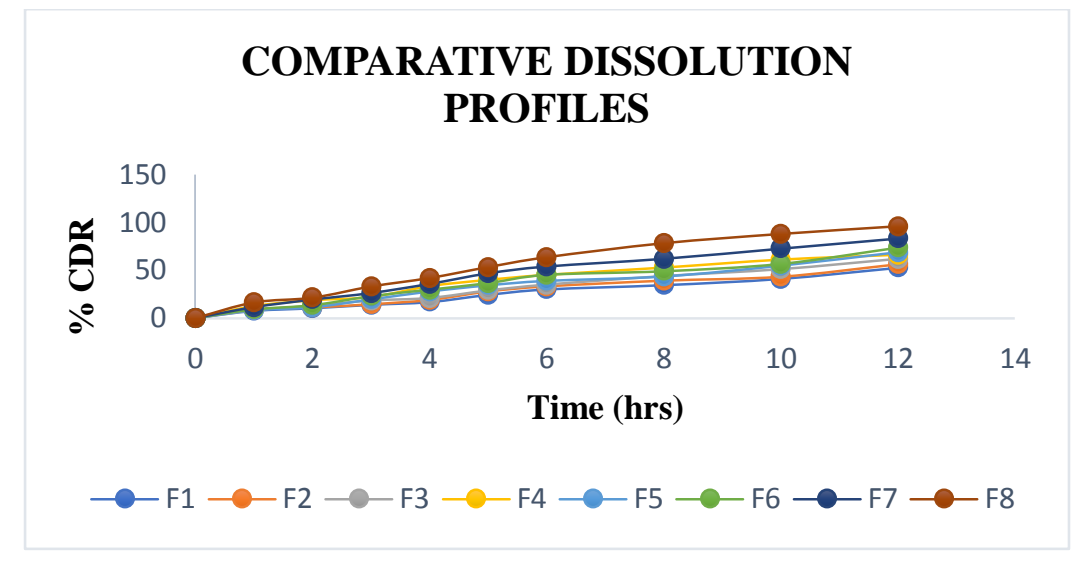

Fig 4. Comparative dissolution profiles

\subsection{Evaluation of Niosomal Gel}

The best niosomal formulation prepared by transmembrane $\mathrm{pH}$ gradient drug uptake process of tween 80: cholesterol (5:5) was selected to formulate into topical gel. The gel was evaluated clarity, pH, homogenecity, viscosity, and spreadability. The prepared gel formulations were found to be clear, $\mathrm{pH}$ was in the range between 6.7-6.9, the formulations were homogenous and spreadability was found to be $3.24 \mathrm{~g} / \mathrm{sec}$ and viscosity was found to be $8569 \mathrm{cps}$. The drug content of formulations werewithin range (88.66-97.86).

\section{Anti-microbial activity:}

From the results of antimicrobial activity, the zone of inhibition of niosomal gel is more than that of plain gel. The results were shown in the table 4 and fig 5 .

\section{Table 3. Antimicrobial studies for Gel formulations}

\begin{tabular}{|l|l|l|}
\hline Test organism & Formulation & Zone of inhibition (mm) \\
\hline Staphylococcus aureus & Standard Gel & 0.5 \\
\hline Staphylococcus aureus & Niosomal Gel & 1.2 \\
\hline
\end{tabular}

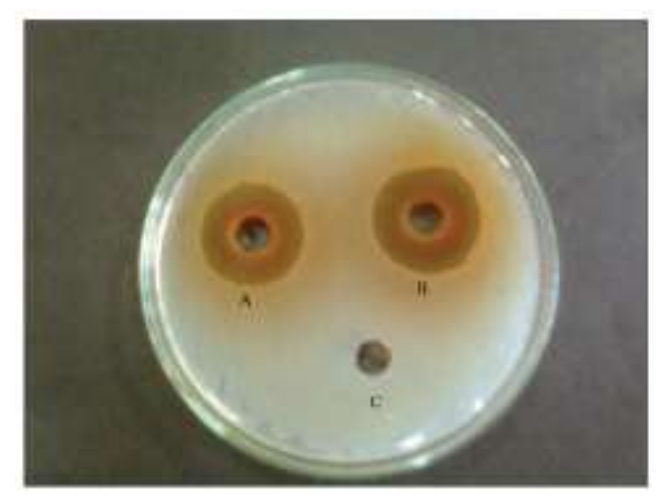

Fig 5. Zone of inhibition images

\subsection{In-vitro drug diffusion studies:}

The in-vitro drug diffusion studies of gel formulations was carried out using Franz diffusion cell. The release of niosomal gel was compared with that of plain gel. The niosomal gel was found to sustain the drug release up to $12 \mathrm{hrs}(98.04 \%)$ when compared to plain gel containing pure drug. The drug release studies were shown in the table 5 and fig 6. 
Table 5. Comparative dissolution profiles of gel formulations

\begin{tabular}{|l|l|l|}
\hline Time (hrs) & Standard Gel & Niosomal Gel \\
\hline 0 & 0 & 0 \\
\hline 1 & $8.92 \pm 0.53$ & $9.81 \pm 0.66$ \\
\hline 2 & $13.04 \pm 0.87$ & $15.62 \pm 0.98$ \\
\hline 3 & $19.56 \pm 0.13$ & $21.09 \pm 0.14$ \\
\hline 4 & $26.68 \pm 0.16$ & $31.10 \pm 0.21$ \\
\hline 5 & $38.90 \pm 0.06$ & $41.21 \pm 0.16$ \\
\hline 6 & $49.68 \pm 0.21$ & $49.83 \pm 0.25$ \\
\hline 8 & $65.70 \pm 0.25$ & $66.14 \pm 0.32$ \\
\hline 10 & $79.57 \pm 0.31$ & $87.68 \pm 0.46$ \\
\hline 12 & $91.09 \pm 0.51$ & $98.04 \pm 0.09$ \\
\hline
\end{tabular}

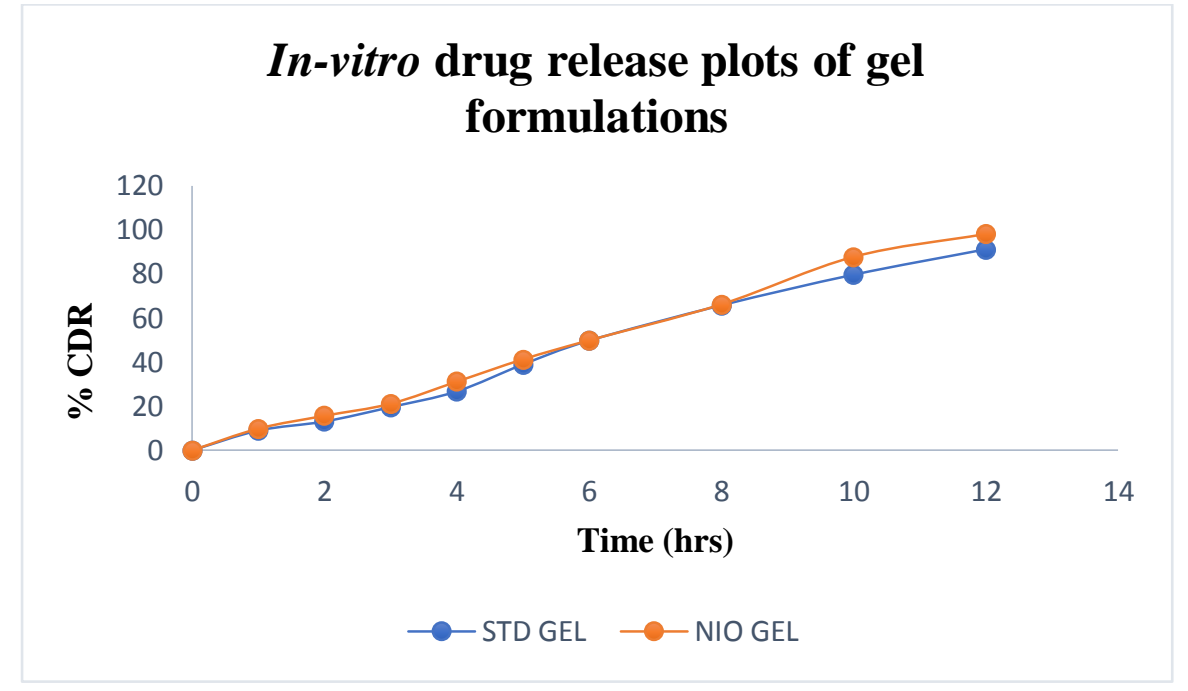

Fig 6 cumulative percent drug release profiles of gel formulations

\subsection{Comparison of plain gel and niosomal gel formulation with various kinetic model}

Plain gel was compared with that of niosomal gel in figure 7. Kinetic plots were compared. Several plots (Zero order plot, first order plot, higuchi plot, erosion plot and peppas plots) were drawn for the gel formulations of plain gel and niosomal gel in order to know the release kinetics and drug release mechanism. From the results it was concluded that the drug release was following zero order kinetics and fitted into korsmeyer equation revealing Non fickian diffusion super case II transport mechanism.

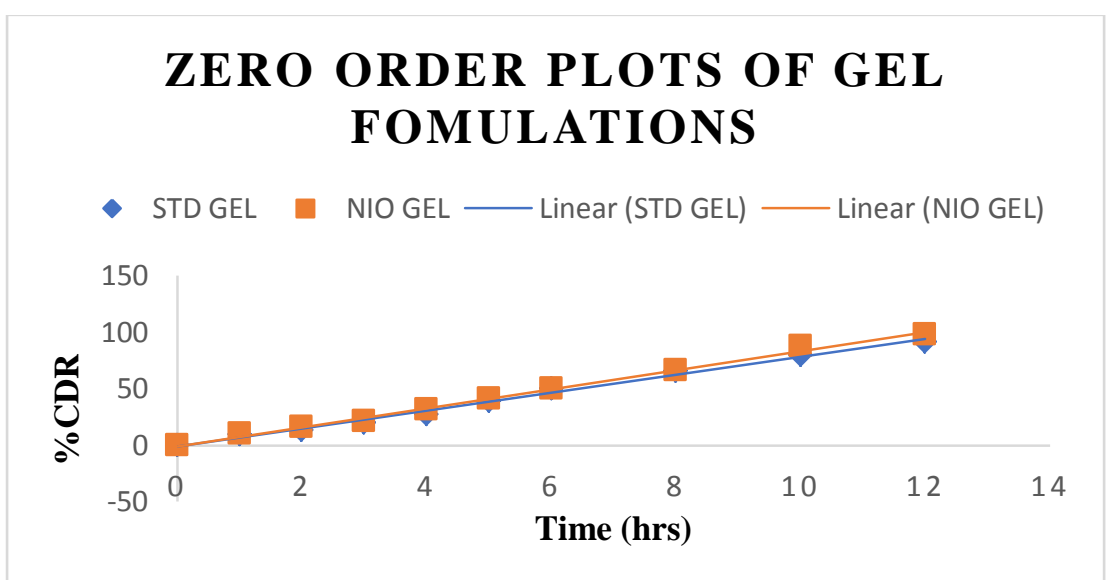



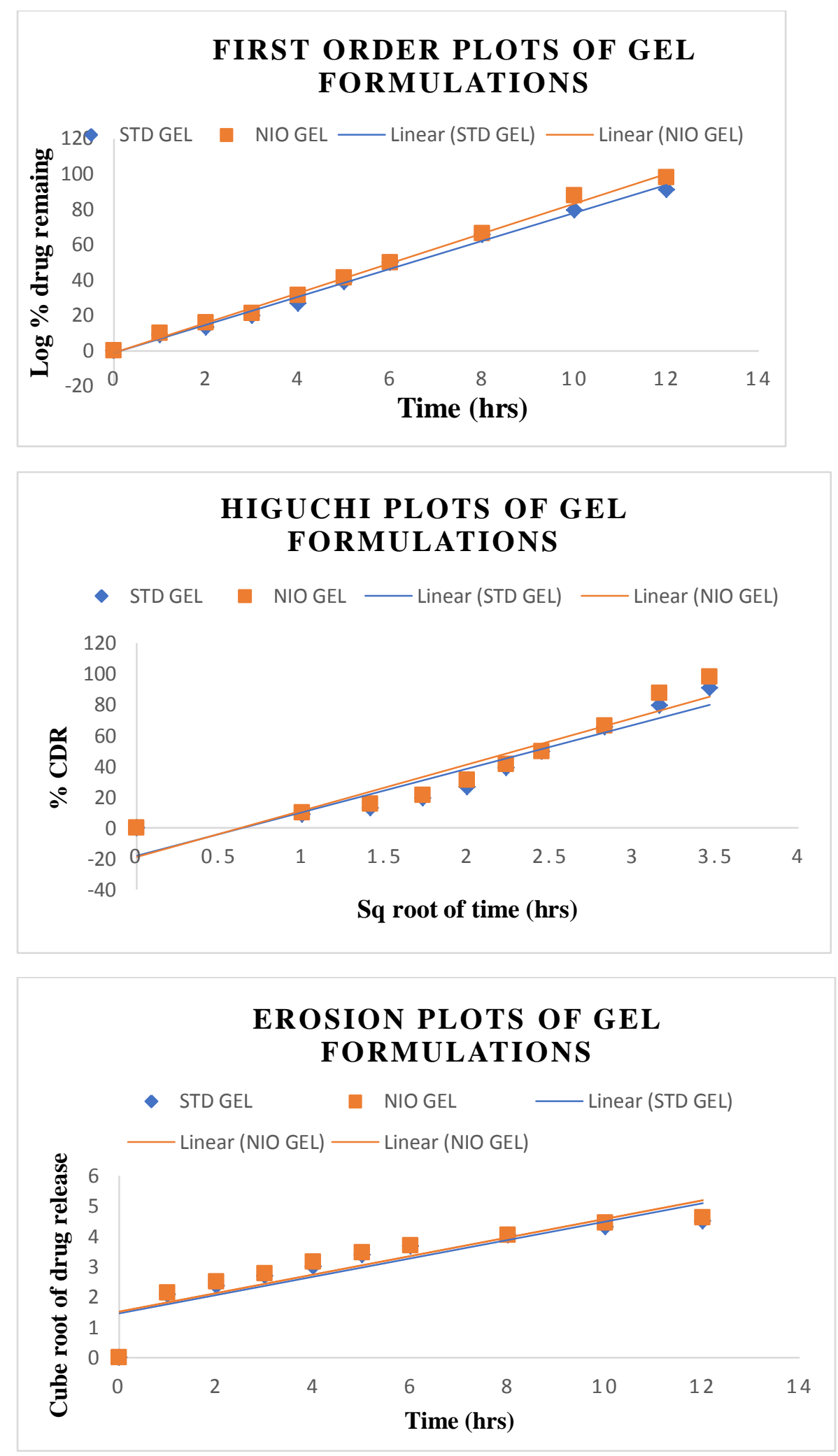


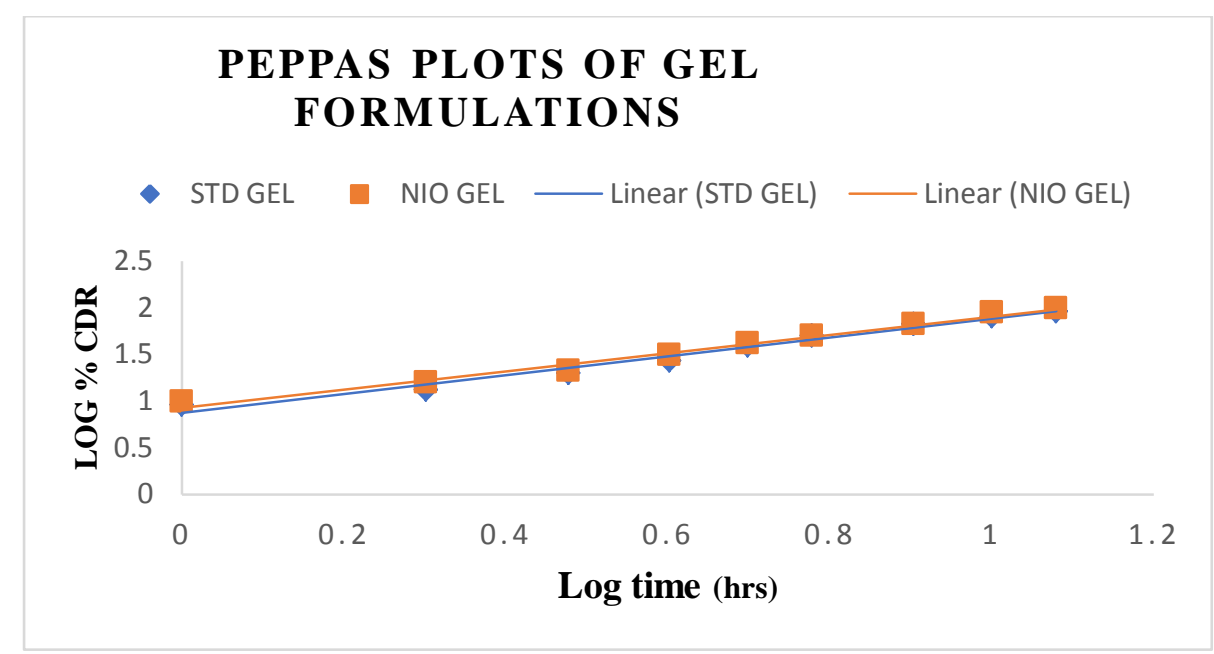

Fig 7. Comparison of gel formulations of plain gel and nioosmal gel with various kinetic models

\subsection{Stability studies:}

\begin{tabular}{|l|l|l|l|l|l|l|l|}
\hline \multirow{2}{*}{ Formulation } & \multirow{2}{*}{ Temperature } & \multicolumn{2}{|l|}{ Initial } & \multicolumn{2}{l|}{ After 30 days } & \multicolumn{2}{l|}{ After 60 days } \\
\cline { 3 - 8 } & & $\begin{array}{l}\text { Drug content } \\
\text { \% }\end{array}$ & $\mathbf{p H}$ & $\begin{array}{l}\text { Drug } \\
\text { content \% }\end{array}$ & pH & $\begin{array}{l}\text { Drug } \\
\text { content \% }\end{array}$ & pH \\
\hline \multirow{3}{*}{ Standard Gel } & $4-8^{\circ} \mathrm{C}$ & $90 \%$ & 6.54 & $89.43 \%$ & 6.52 & $87.1 \%$ & 6.39 \\
\cline { 2 - 8 } & $25 \pm 2^{\circ} \mathrm{C}$ & $90 \%$ & 6.54 & $89.43 \%$ & 6.52 & $87.1 \%$ & 6.39 \\
\hline Niosomal gel & $4-8^{\circ} \mathrm{C}$ & $96 \%$ & 6.25 & $94 \%$ & 6.10 & $92 \%$ & 6.82 \\
\cline { 2 - 7 } & $25 \pm 2^{\circ} \mathrm{C}$ & $96 \%$ & 6.25 & $94 \%$ & 6.10 & $92 \%$ & 6.82 \\
\hline
\end{tabular}

\section{Discussions}

\section{Effect of surfactants and cholesterol}

Surfactants play major role for the entrapment of drugs. Among all formulations F8 (1:5:5, Drug: surfactant: cholesterol) showed maximum entrapment efficiency by transmembrane $\mathrm{pH}$ gradient method. The entrapment efficiency increased in the order of tween $80\left(\mathrm{C}_{18}\right)>$ span80 $\left(\mathrm{C}_{18}\right)$ this could be due to the surfactant chemical structure. Tween 80 and span 80 have the same head groups but span 80 has an unsaturated alkyl chain. In addition span 80 has the lowest transition temperature $\left(-12^{\circ} \mathrm{c}\right)$ compared to tween 80 . The order of Entrapment efficiency increased as the lipophilicity of the surfactant increased. Here tween 80 contains higher HLB value (15.0) than span 80 (4.3) and it contains unsaturated alkyl chain in its structure leads to lowest entrapment efficiency.

Cholesterol is used as a membrane additive, acts as stabilizer as well asfluidity buffer to improve the stability of the vesicles. The formulations were prepared using non-ionic surfactants by varying surfactant concentration and keeping the cholesterol concentration fixed.

\section{Conclusion}

The purpose of this research was to prepare mupirocin loaded niosomes for controlled release of drug and incorporated it into topical gel drug delivery system to reduce the side effects. Transmembrane $\mathrm{pH}$ gradient method an ether injection method was employed to produce niosomes using non-ionic surfactants and cholesterol. Gel formulations were prepared containing pure drug (plain gel) and niosomal gel. Comparison studies were made between both the gel formulations and evaluation parameters like drug content, homogeneity, spreadability, PH, clarity, in vitro diffusion studies were studied. The niosomal gel showed good physical properties and optimum drug release pattern up to $12 \mathrm{hrs}$ with $98.04 \%$ with highest drug content of 96\% when compared with plain gel formulation. The kinetic data analysis revealed that the formulated gel 
follows Zero order release kinetics. The Higuchi's plot for the formulation indicated that the predominant mechanism of drug release is diffusion and the data were fitted according to the Korsmeyer-Peppa's model indicated that the drug permeation from the niosomal gel followed non-fickian diffusion super case II transport mechanism. It was concluded that the transmembrane $\mathrm{pH}$ gradient method is useful method for the successful incorporation of poorly water-soluble drug mupirocin into niosomes with high entrapment efficiency. The prolonged release of the drug from the noisome suggests that the frequency of administration and adverse effects significantly thereby improving the patient compliance. The administration of drug as gel type formulation enhances its penetration and release. The niosomal gel showed better properties than the mupirocin plain gel indicating a promising gel as an alternative to the conventional dosage forms.

\section{References}

1. Vyas and Khar S.P.Vyas and R.K.Khar, 2004, Niosomes, Targetted \& Controlled Drug delivery Systems, Novel Carrier Systems, 250,286. Vallabh Prakashan,Delhi.

2. $\quad$ Namedo Alok and Jain, N.K., Niosomes as drug carriers,Ind J.Pharm.Sci.,1996,58(2),4146.

3. Vanlerberghe, G. and Morancias, J.L., Niosomes in perspective, S.T.P. Pharma Sciences, 1996,6(1),511.

4. $\quad$ Fendler, J.H., Membrane Mimetic Chemistry, Wiley Inter.Sci, 1982, 158.

5. A. K. Verma and J. C. Bindal, "A vital role of niosomes on controlled and novel drug delivery," Indian Journal of Novel Drug Delivery, vol. 3, pp. 238-246, 2011. View at Google Scholar

6. Didem Ag Seleci, MuharremSeleci, Johanna-Gabriela Walter. Niosomes as nanoparticular drug carriers: Fundamentals and recent applications. Journal of nanomaterials vol 2016.

7. Kasim NA, Whitehouse M, Ramachandran C, Bermejo M, Lennernas H, Hussain AS, Junginger HE, Stavchansky SA, Midha KK, Shah VP, Amidon GL. 2004. Molecular properties of WHO essential drugs and provisional biopharmaceutical classification. Mol Pharm 1(1):85-96.

8. Dobashi A. 2008. Pharm I.S.-Lamivudine. Department of Pharmaceutical Information Science. Available at: http:// www.pharmis.org/.

9. Kashuba AD, Dyer JR, Kramer LM, Raasch RH, Eron JJ, Cohen MS. 1999. Antiretroviral-drug concentrations in semen: Implications for sexual transmission of human immunodeficiency virus type 1 . Antimicrob Agents Chemother 43(8):1817-1826.

10. Gibbs JE, Rashid T, Thomas SA. 2003. Effect of transport inhibitors and additional anti-HIV drugs on the movement of lamivudine (3TC) across the guinea pig brain barriers. J Pharmacol Exp Ther 306(3):1035-1041

11. Jozwiakowski MJ, Nguyen NA, Sisco JM, Spancake CW. 1996. Solubility behavior of lamivudine crystal forms in recrystallization solvents. J Pharm Sci 85(2):193-199.

12. D. Akhilesh, K. B. Bini, and J. V. Kamath, "Review on span-60 based non-ionic surfactant vesicles (niosomes) as novel drug delivery," International Journal of Research in Pharmaceutical and Biomedical Sciences, vol. 3, pp. 6-12, 2012.

13. SorlinSelvaJoice P, Rubina Reichal C, Thirumoorthy N and Sangeetha M. Formulation and evaluation of tetracycline niosomal topical gel drug delivery system. World J of Pham \&pham.sci Volume 6, Issue 8, 2017.

14. Anbarasan B, Rekha S, Elango K, Shriya B, Ramaprabhu S. Optimization of the formulation and invitro evaluation of capecitabine niosomes for the treatment of color cancer. IJPSR. 2013; 4(4): 5041513.

15. Sera UV, Ramana MV, In vitro skin absorption and drug release-a comparison of four commercial hydrophilic gel preparations for topical use. The Indian Pharmacist 2006;73:356-360.

16. Bhalaria M, Naik S, Misra A. A novel delivery system for antifungal drugs in the treatment of topical fungal disease. Indian J Exp Biol 2009; 47(5):368-75.

17. Rajera R, Nagpal K, Kumar S, Mishra DN. Niosomes: A controlled and novel drug delivery system. Biol. Pharm Bull. 2011; 34(7): 945953.

18. K. Srikanth Gupta, M. Nappinnai, Dr.V.R.M. Gupta. Formulation and evaluation of topical meloxicam niosomal gel. International Journal of Biopharmaceutics. 1; 2010: 7-13. 